\title{
Effect of early intervention on 5-year outcome in non-affective psychosis ${ }^{\dagger}$
}

Rafael Gafoor, Dorothea Nitsch, Paul Mccrone, Tom K. J. Craig, Philippa A. Garety, Paddy Power and Philip McGuire

\section{Background}

Early specialised care may improve short-term outcome in first-episode non-affective psychosis, but it is unclear if these benefits endure.

\section{Aims \\ To assess the long-term effect of early intervention in psychosis.}

\section{Method}

Individuals with first-episode psychosis were randomised to specialised care or care as usual (trial number:

ISRCTN73679874). Outcome after 5 years was assessed by case-note review.

\section{Results}

There were no significant differences in the admission rate (coefficient $0.096,95 \% \mathrm{Cl}-0.550$ to $0.742, P=0.770$ ) or the mean number of bed days (coefficient $6.344,95 \% \mathrm{Cl}-46$ to 58.7, $P=0.810$ ).

\section{Conclusions}

These findings that specialist intervention did not markedly improved outcome at 5 years accord with those from a larger OPUS study. The sample size of this study was small and these results should be generalised with caution. More research is needed.

\section{Declaration of interest}

None.
Specialist services aim to reduce hospitalisation in patients with psychosis by initiating treatment as soon as possible after the first episode. ${ }^{1}$ In the OPUS study, ${ }^{2}$ participants with first-episode psychosis randomised to specialist services had shorter hospital admissions at 1 year after presentation than those assigned to care as usual; however, these benefits did not endure at 2-year follow-up. The Lambeth Early Onset (LEO) trial ${ }^{3}$ found that individuals treated by a specialist service had lower hospital bed use at 18 months than those receiving care as usual. Whether the beneficial effects of specialist services endure in the longer term is unclear. We addressed this issue by following up participants in the LEO trial 3.5 to 5 years after inception. The trial was registered with the International Standard Randomised Controlled Trial Number Register and was assigned the trial number ISRCTN73679874.

\section{Method}

\section{Initial study - randomised controlled trial}

In 2002, 144 people presenting to psychiatric services in Lambeth, South London, with a first or second episode of non-affective psychosis were randomly allocated to either 'specialist services' or 'care as usual by community mental health teams (CMHTs)' at inception. Inception was defined as the point of first treatment for psychosis. Inclusion required an age of 16-40 years, and a presentation of a non-affective psychosis (schizophrenia, schizotypal, and delusional disorders, F20-29 in the ICD-10). ${ }^{4}$ Individuals with an 'organic' psychosis or a primary alcohol or drug addiction were excluded. Participants were randomised by permuted random blocks of between two and six. The randomisation and concealment group allocation was carried out by sealed envelope method by the trial statistician. Follow-up interviews were conducted at 18 months (while the participant was still receiving care from the original clinical teams). Data on

†See pp. 377-382, this issue. readmissions were obtained from centralised computer case records and from interview with psychiatric care coordinators. Follow-up information on clinical status at 18 months was collected from 131 (91\%) people.

The specialist team (LEO) was a new service comprising 10 mental health professionals who delivered specialised interventions including low dose atypical antipsychotic regimens, cognitive-behavioural therapy based on manualised protocols, ${ }^{5-7}$ family counselling and vocational strategies based on established protocols. ${ }^{89}$ Participants in the control group received standard care from established adult general CMHTs in Lambeth. These teams had received no formal training in specialist interventions but had access to guidelines on the approach. ${ }^{8,10}$

Although participants and clinicians were not masked to treatment arm, it is unlikely that participants had contact with other participants in the other arm. Allocation remained undisclosed until completion of the ratings. However, assessors were able to guess the arm of treatment to which $60 \%$ of participants had been allocated ( $95 \%$ CI 52 to $63, \kappa=0.20$ ).

Participants were analysed by intention-to-treat analysis (ITT) in the group to which they were initially randomised. Regression analyses were adjusted for variables that were unbalanced between the two groups at baseline (ethnicity, past episode and gender).

\section{Results from the initial study}

A previous study ${ }^{3}$ had found that individuals receiving specialist treatment had fewer admissions in the intervening 18-month review period than those assigned to care as usual: (0.4 admissions v. $0.8(\beta=0.36,95 \%$ CI 0.04 to $0.66, P=0.030))$, but were not less likely to have ever been admitted $(\mathrm{OR}=0.53,95 \% \mathrm{CI} 0.26$ to 1.12 , $P=0.095)$ or to have had shorter admissions $(\beta=19.4,95 \% \mathrm{CI}$ -10.6 to $48.6, P=0.197)$. Participants treated by the specialist team had better social and vocational functioning (mean 6.9 months in employment for the specialist group $v$. mean of 4.2 months, $P=0.008$ ), quality of life (mean score of 59.2 for specialist services $v$. mean score of $53.3, P=0.010)$ and medication 
adherence (mean adherence score of 5.4 for specialist services $v$. mean score of $4.5, P=0.036$ ) at 18 months).

\section{Follow-up study}

In 2005, the above participants were retrospectively assessed during an 18 -month period (3.5 to 5 years after inception). The primary (null) hypothesis was that there would be no difference in the odds of having ever been admitted in the 18 months prior to this second assessment. The secondary (null) hypotheses were that the relative admission rates and the length of bed occupancy during this period would be the same for both groups.

Ethical permission for this study was given by the Institute of Psychiatry at the Maudsley (Kings College London, University of London). Ethical permission for the analysis of the data was given by the ethical committee of the London School of Hygiene and Tropical Medicine, University of London. Clinical ethical permission for participants to be traced, contacted and interviewed was given by the South London and Maudsley NHS Mental Health Trust (SlaM).

We assumed that the relative reduction in the rate of ever having been admitted would decrease by $10 \%$ in the next 5 years as the effects of specialist services waned; there are no comparative admission data currently available at 5 years for individuals who were exposed to specialist services as this is the first follow-up study of such a randomised cohort. Using data from clinical audit, the rate of ever having been admitted for individuals in 'care as usual' CMHTs is approximately $65 \%$ over 18 months at 5 -year follow-up. We assumed a relative reduction in the rate of ever having been admitted of $23 \%$ between the two groups and a rate of $46 \%$ of ever having been admitted (for people who had been randomised to the specialist group) over the 18-month period leading up to 5 years post first admission. At a power of $80 \%$ and an alpha of 0.05 , we determined that 234 people would be required in total to find a difference between the two groups if one existed. If all 144 individuals had been traced, the study would have a power of $56 \%$ of discovering a difference between the groups if such a difference existed at an alpha of 0.05 . This study was underpowered but it is no longer possible to increase the sample size given that it would be unethical to randomise individuals again to care as usual. This follow-up study (although imperfect) provides the best evidence currently available in the clinical circumstances.

An extensive sequential tracing algorithm was used to find participants: individuals were traced using electronic patient records held by the local National Health Service (NHS) trust, the NHS Strategic Tracing Service (NSTS), land registry records, general practitioner (GP) records, the UK register of deaths or via the last known relative. We were not able to access prison records or Home Office immigration records for deported individuals. Migrants and prisoners may have had worse prognoses and more admissions than other people; differential loss to follow-up for this subgroup may have resulted in an 'emigration bias. ${ }^{11-15}$ Follow-up was not masked to intervention arm as individuals often disclosed their treatment on interview and treatment group was apparent on review of the notes. Poor concealment was also an issue in the original LEO trial (as discussed above). To reduce the chance of information bias, dates of recorded admissions and the number of documented admissions were used as the primary sources for data collection. Information was verified by reference to written material or by reference to the team treating the individual.

All traced participants were successfully contacted (including those living overseas), and all agreed to provide follow-up information. Individuals were given information about the study

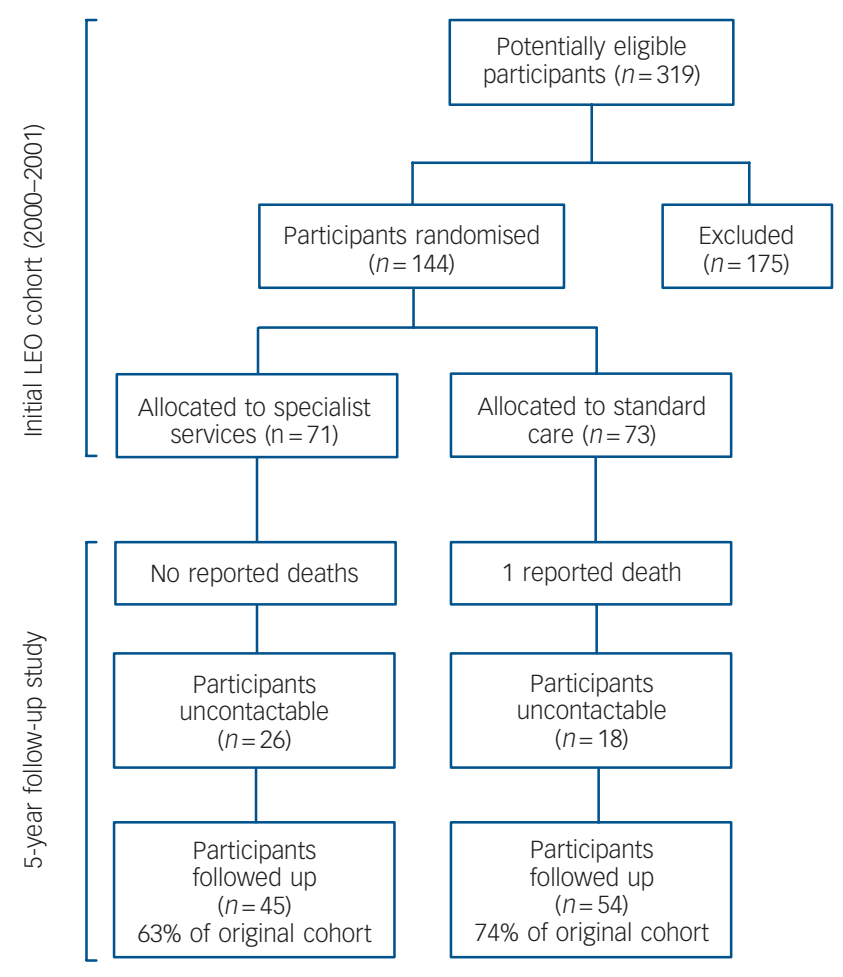

Fig. 1 Participant flow.

Reasons for exclusion: not resident in Lambeth, too old or too young $(n=38)$; did not meet diagnostic criteria $(n=90)$; already engaged with services $(n=35)$; lost before confirmed $(n=12)$

on the telephone and this was followed up by written materials where requested. Participants were interviewed on the telephone or in person (whichever method they preferred). Figure 1 shows that of the original 144 participants who were randomised, 99 $(69 \%)$ were traced and contacted. In comparison, Nordentoft et al in their 5-year follow-up study of service interventions in Denmark were able to contact 301 participants (55\%) out of an incipient cohort of $547 .^{16}$

To remove the potential influence of differential access to home treatment teams on hospital admission rates (as it is often provided as an alternative to admission), all home treatment team events were counted as equivalent to an admission. Where the home treatment team care was provided in isolation, the case was recorded as an admission with the length of home treatment counting as the length of hospital admission. In some cases, individuals initially receiving home treatment teams were then admitted: in this case, home treatment and hospital admission were counted as a single admission event. The total time of admission was the time in hospital plus the time with home treatment teams. The same algorithm was used for individuals who were discharged from the ward directly to home treatment teams.

Diagnoses were assigned at a median time of 5.3 years and were made using a notes-based diagnostic tool, the operational criteria OPCRIT checklist ${ }^{17}$ for psychotic and affective illness, which provided diagnoses according to the ICD-10 system. ${ }^{4}$

Analyses were performed using STATA release 9 on Windows Vista. Linear regression models were employed to assess the relationship between initial randomisation group and outcome variables. There were two potential sources of confounding: failure of randomisation to produce balanced groups in the original LEO trial and differential contactability between treatment arms. 
(Details of the strategy for analysis for confounding and the results of these analyses are contained in the online supplement.) A sensitivity analysis was performed to assess the robustness of the findings when participants who could not be traced were assigned extreme values.

\section{Results}

Figure 1 shows the participant flow for both the original trial in 2000 and during the 18 -month period of follow-up (i.e. 3.5 to 5 years after inception). One person died due to accidental causes. Of those who had been randomised to care as usual, $15(28 \%)$ v. $15(33 \%)$ of those who had been allocated to the specialist team had been discharged to their GP (Pearson $\chi^{2}=0.359, P=0.549$, d.f. =1). The length of time for which individuals were with their GP after discharge from services was highly skewed. Participants in specialist services who had been discharged to their GP spent a median of 0 days (IQR $=0-826)$ with their GP $v$. a median of 0 days (IQR $=0-264$ ) for those randomised to care as usual. There was no significant difference in the length of time spent with their GP for either group (Mann-Whitney $U=1147.5, Z=-0.571$, $P=0.568$ ). Participants treated by the specialist service were followed up by psychiatric services for a median of 1778 days $(\mathrm{IQR}=1152-2030)$ after first randomisation $v$. a median of 1887 days (IQR $=1640-2034$ ) for those randomised to care as usual. There was no statistically significant difference in the length of time spent in psychiatric services for either group $(U=1077.5$, $Z=-0.973, P=0.330)$. Individuals randomised to specialist services spent a median of 861 days in the specialist service (IQR $=720-1027)$. In total, 99 participants (70\%) were successfully traced from the original cohort. By comparison, Nordentoft et $\mathrm{al}^{16}$ in their 5-year follow-up were able to contact only 301 participants (55\%) of an incipient cohort of 547, underscoring the difficulties of follow-up in this cohort.

The followed-up participants were representative of the original LEO sample (Table 1). Contactable participants were not significantly different in baseline clinical variables from those who were traced (see online supplement). Analysis for confounding (see online supplement for details) identified that 'ever having been discharged from psychiatric services to a GP' was a confounder in the relationship between whether of not a participant could be contacted and the main outcome of ever having been admitted. We also adjusted for imbalances in baseline variables: gender, previous psychotic episodes and ethnic group.

Table 2 shows the cross-sectional differences between the two groups during the 18 -month follow-up (i.e. from 3.5 to 5 years post-inception) at baseline. There was no difference in the chances of any admission, the number of admissions or the number of bed days used during the follow-up period. We noted that there was an increase in the number of admissions during the follow-up period relative to the initial review period. This increase was attributable to an increased admission rate for each individual relative to that during the initial follow-up period. Thus, during the second follow-up period, $21 \%$ of people were not admitted, $49 \%$ were admitted once, $20 \%$ were admitted twice and $8 \%$ were admitted three or more times. The reason for the increased number of admissions during this period is unclear. It may reflect changes in service structures over the period of the study, and/or a change in the pattern of service use or need as psychotic illnesses become more chronic.

Regression modelling was employed to estimate effect size of interventions and to allow for adjustment with potential confounding factors.

Although the data were not normally distributed, because the data from the original LEO trial used a parametric analysis, we

\begin{tabular}{|c|c|c|}
\hline & $\begin{array}{l}\text { Original cohort } \\
\text { baseline } \\
\text { characteristics } \\
\quad(n=144)\end{array}$ & $\begin{array}{c}\text { Baseline } \\
\text { characteristics } \\
\text { of participants } \\
\text { traced } 5 \text { years later } \\
\quad(n=99)^{\mathrm{a}}\end{array}$ \\
\hline \multicolumn{3}{|c|}{$\begin{array}{l}\text { Age at baseline, years: } \\
\text { median (IOR) }\end{array}$} \\
\hline Male, $n(\%)$ & $93(65)$ & $60(60)$ \\
\hline \multicolumn{3}{|l|}{ Ethnicity, $n$ (\%) } \\
\hline White & $45(31)$ & $28(28)$ \\
\hline Black British & $16(11)$ & $15(15)$ \\
\hline Black Caribbean & $22(15)$ & $15(15)$ \\
\hline Black African & $41(28)$ & $25(25)$ \\
\hline Mixed & $12(8)$ & $9(9)$ \\
\hline Other & $8(5)$ & $7(7)$ \\
\hline Single, $n(\%)$ & $100(69)$ & 69 (69) \\
\hline First episode, ${ }^{\mathrm{b}} n(\%)$ & $113(78)$ & $73(73)$ \\
\hline \multicolumn{3}{|l|}{ Living situation, $n$ (\%) } \\
\hline Family & $77(54)$ & $65(65)$ \\
\hline Alone & $41(28)$ & $26(26)$ \\
\hline Other ${ }^{\mathrm{c}}$ & $24(17)$ & $8(8)$ \\
\hline \multicolumn{3}{|l|}{ Employment, $n$ (\%) } \\
\hline Full time & $17(12)$ & $8(8)$ \\
\hline Part time & $9(6)$ & $7(7)$ \\
\hline Unemployed & $90(63)$ & $55(55)$ \\
\hline Migrant, n (\%) & 56 (39) & $38(38)$ \\
\hline \multicolumn{3}{|c|}{$\begin{array}{l}\text { a. Percentages based on traceable population of } 99 \text {. } \\
\text { b. Inclusion criteria for the incipient cohort allowed participants to have had a } \\
\text { previous psychotic episode, providing it had been untreated and the individual had } \\
\text { subsequently disengaged from clinical services. } \\
\text { c. Living with friends or living in a hostel. }\end{array}$} \\
\hline
\end{tabular}

replicated this analysis so that the results during the initial and subsequent 18 -month periods could be more directly compared.

Data on number and length of admission during the 18month period leading to 5 years were highly skewed. The median number of admissions was identical in both groups (median 0 , $\mathrm{IQR}=0-1)$. The mean number of bed days was 42.25 days (s.d. $=112.8$, median $0, \mathrm{IQR}=0-31.0)$ and 51.41 days (s.d. $=125$, median $0, \mathrm{IQR}=0-38.0$ ) in the 'specialist services' and 'care as usual' groups respectively.

Table 3 shows the relationship between outcome and randomisation group for crude and adjusted regression modelling. There were no significant differences between the two groups in terms of any of the outcome measures before and after adjusting for confounders.

\section{Sensitivity analysis}

In total, 26 participants in the specialist services arm and 18 people in the care as usual arm could not be traced at 5-year follow-up. We performed sensitivity analyses on the data from these missing individuals to examine the robustness of the finding from the initial logistic regression model that there was no group difference in ever having been admitted (see online supplement). We calculated that the finding of no observed differences in the odds of being admitted between the two groups would only be reversed if at least $80 \%$ of those who were missing from the specialised care group and had been admitted as well as if $20 \%$ of missing participants from the care as usual group had also ever been admitted (see online supplement). This is an unlikely scenario and uncontactable individuals in the specialised care arm would have to have been twice as likely to have ever been 
Table 2 Primary outcome measures for participants receiving specialised care or standard care for early psychosis

\begin{tabular}{|c|c|c|c|c|c|c|}
\hline & \multicolumn{3}{|c|}{ 18-month follow-up starting from time of entry } & \multicolumn{3}{|c|}{ 18-month follow-up starting 3.5 years after first entry } \\
\hline & Specialised care group & Standard care group & $P$ & Specialised care group & Standard care group & $P$ \\
\hline Any readmissions, $n$ (\%) & $23(33)$ & $33(51)$ & $<0.001^{\mathrm{a}}$ & $18(33)$ & $17(39)$ & $0.160^{\mathrm{a}}$ \\
\hline Admissions, mean (s.d.) $)^{b}$ & $0.4(0.7)$ & $0.8(1.0)$ & $0.010^{\mathrm{C}}$ & $1.65(0.86)$ & $1.83(0.92)$ & $0.56^{\mathrm{c}}$ \\
\hline Bed-days in follow-up, mean (s.d.) & $35.5(78.9)$ & $54.9(93.6)$ & $0.42^{C}$ & $45.25(112.8)$ & $51.41(125)$ & $0.88^{\mathrm{C}}$ \\
\hline \multicolumn{7}{|c|}{$\begin{array}{l}\text { a. Pearson } \chi^{2} \text {-test. } \\
\text { b. Some participants were initially admitted at time of presentation mainly because of risk considerations. To remove bias when comparing admissions with individuals who were } \\
\text { initially incepted into the study in the community, the initial admission at baseline was not counted. } \\
\text { c. Student's } t \text {-test. }\end{array}$} \\
\hline
\end{tabular}

\begin{tabular}{|c|c|c|c|c|c|c|}
\hline Predictor variable & $\begin{array}{l}\text { Crude regression } \\
\text { coefficient or } \mathrm{OR}^{\mathrm{a}}\end{array}$ & $95 \% \mathrm{Cl}$ & $P$ & $\begin{array}{l}\text { Adjusted regression } \\
\text { coefficient or } \mathrm{OR}^{\mathrm{b}}\end{array}$ & $95 \% \mathrm{Cl}$ & $P$ \\
\hline Ever admitted ${ }^{c}$ & 1.26 & 0.549 to 2.89 & 0.586 & 1.24 & 0.460 to 3.34 & 0.670 \\
\hline Number of admissions ${ }^{d}$ & 0.040 & -0.463 to 0.544 & 0.875 & 0.006 & -0.542 to 0.555 & 0.981 \\
\hline Length of stay, ${ }^{e}$ days & -6.16 & -54.3 to 42.0 & 0.800 & 2.15 & -50.4 to 54.7 & 0.935 \\
\hline \multicolumn{7}{|c|}{$\begin{array}{l}\text { a. Odds ratio of outcome for participants in specialist services } v \text {. those in care as usual. } \\
\text { b. Adjusted for any previous psychotic episode, ethnicity and gender. } \\
\text { c. Modelled using logistic regression. } \\
\text { d. Modelled using Poisson regression. } \\
\text { e. Modelled using linear regression with robust standard errors. }\end{array}$} \\
\hline
\end{tabular}

admitted as those from the specialised care arm who were traced. We discounted the scenarios where all or none of those people who could not have been traced had been admitted in either arm as being unlikely.

We examined the stability of the initial diagnosis of 'nonaffective psychosis' that had been made 5 years previously when the participants took part in the original LEO study. Data were extracted from case notes and used in the OPCRIT algorithm to produce ICD-10 diagnoses. Table 4 shows the ICD-10 diagnostic category assigned by OPCRIT at the time of follow-up. The median time from entry into the study to diagnosis was 64.2 months (5.3 years) (IQR $=58.3-64.2$ months). Of those who could be accorded a diagnosis at follow-up, more than $85 \%$ of them continued to be diagnosed with a psychotic illness.

\section{Discussion \\ Limitations}

The power of the study to detect statistically significant differences between the two groups was low. However, this is not surprising given that the benefits of specialised services did not persist during the period of 3.5 to 5 years post-inception and relative differences between the two groups became smaller. Only a restricted range of clinical outcomes were assessed and potential benefits in other outcome domains may persist.

The study was conducted in an urban population with a relatively high incidence of psychosis, and high levels of poverty, unemployment and illicit drug use. The risk of developing psychosis and of relapsing after a first episode in this population may not be representative of the UK overall. Given these limitations, the results of this study should be generalised to other populations with caution.

\section{Clinical implications}

Although there is good evidence that specialised intervention in first-episode psychosis improves outcomes in the first $1-2$ years, ${ }^{3}$ the extent to which these benefits persist in the longer term remains unclear, particularly after the specialised intervention is withdrawn.

\begin{tabular}{|lc|}
\hline Table 4 Diagnoses at follow-up & \\
\hline Diagnosis (ICD-10) & $n(\%)$ \\
\hline Schizophrenia, schizotypal, and delusional disorders & $57(58)$ \\
\hline Other & $5(5)$ \\
\hline Bipolar disorder & $3(3)$ \\
\hline Depressive illness & $2(2)$ \\
\hline Psychosis (not otherwise specified) & $1(1)$ \\
\hline No diagnosis accorded & $1(1)$ \\
\hline Sufficient information not available to give diagnosis & $30(30)$ \\
\hline
\end{tabular}

\section{Prodromal therapies}

Prodromal interventions (before the onset of the first psychotic episode) may improve outcomes but at least two systematic reviews ${ }^{18,19}$ conclude that the combined results of prodromal interventions are equivocal. More research on the efficacy of prodromal services is needed.

\section{Future research}

Aside from limited statistical power, the absence of a difference in outcome between the two groups at 5-year follow-up may reflect the withdrawal of the specialised intervention after 18 months (when there was a significant group difference); ${ }^{3}$ further investigation of this issue will require trials involving longer durations of specialised treatment. At present, specialised care for psychosis is usually provided for the initial 1-2 years of illness.

Rafael Gafoor, BA, MSC, PhD, MRCPsych, Institute of Psychiatry, Kings Health Partners, London; Dorothea Nitsch, MD, MSC, London School of Hygiene and Tropical Medicine, London; Paul McCrone, PhD, Tom K. J. Craig, PhD, FRCPsych, Philippa A. Garety, MA, MPhil, MA(Ed), PhD, FBPSS, Paddy Power, MD, MRCPsych, Philip McGuire, PhD, FRCPsych, Institute of Psychiatry, King's Health Partners, London, UK

Correspondence: Philip McGuire, Institute of Psychiatry, King's College London, De Crespigny Park, London SE5 8AF, UK. Email: philip.mcguire@kcl.ac.uk

First received 11 Mar 2009, final revision 26 Aug 2009, accepted 16 Sep 2009 


\section{Funding}

This study was funded by the Medical Research Council (UK) via a Clinical Research Training Fellowship to the lead author.

\section{References}

1 Birchwood M, Todd $P$, Jackson C. Early intervention in psychosis. The critica period hypothesis. Br J Psychiatry 1998; 172 (suppl 33): s53-9.

2 Petersen L, Jeppesen $\mathrm{P}$, Thorup A, Abel MB, Ohlenschlaeger J, Christensen TO, et al. A randomised multicentre trial of integrated versus standard treatment for patients with a first episode of psychotic illness. BMJ 2005: 331: 602 .

3 Craig TK, Garety $\mathrm{P}$, Power $\mathrm{P}$, Rahaman N, Colbert S, Fornells-Ambrojo M, et al. The Lambeth Early Onset (LEO) team: randomised controlled trial of the effectiveness of specialised care for early psychosis. BMJ 2004; 329: 1067.

4 World Health Organization. The ICD-10 Classification of Mental and Behavioural Disorders: Clinical Descriptions and Diagnostic Guidelines. WHO, 1992.

5 Jackson H, McGorry P, Edwards J, Hulbert C, Henry L, Francey S, et al. Cognitively-oriented psychotherapy for early psychosis (COPE). Preliminary results. Br J Psychiatry 1998; 172 (suppl 33): 93-100.

6 Jackson $\mathrm{H}$, McGorry P, Henry L, Edwards J, Hulbert C, Harrigan S, et al. Cognitively oriented psychotherapy for early psychosis (COPE): a 1-year follow-up. Br J Clin Psychol 2001; 40: 57-70.

7 Jolley S, Garety P, Craig T, Dunn G, White J, Aitken M. Cognitive therapy in early psychosis: a pilot randomised controlled trial. Behav Cog Psychother 2003; 31: 473-8.

8 Early Psychosis Prevention and Intervention Centre. EPPIC Early Psychosis Training Pack. EPPIC, 1997.
9 Edwards J, McGorry PD. Implementing Early Intervention in Psychosis: A Guide to Establishing Early Psychosis Services. Martin Dunitz, 2002.

10 Aitchison K, Meehan K, Murray RM. First Episode Psychosis. Martin Dunitz, 1999.

11 Brinded PM, Simpson Al, Laidlaw TM, Fairley N, Malcolm F. Prevalence of psychiatric disorders in New Zealand prisons: a national study. Aust N Z J Psychiatry 2001; 35: 166-73.

12 Brugha $T$, Singleton $N$, Meltzer $H$, Bebbington $P$, Farrell $M$, Jenkins $R$, et al. Psychosis in the community and in prisons: a report from the British National Survey of psychiatric morbidity. Am J Psychiatry 2005; 162: 774-80.

13 Butler T, Allnutt S, Cain D, Owens D, Muller C. Mental disorder in the New South Wales prisoner population. Aust N Z J Psychiatry 2005; 39: 407-13.

14 Butler T, Andrews G, Allnutt S, Sakashita C, Smith NE, Basson J. Mental disorders in Australian prisoners: a comparison with a community sample. Aust N Z J Psychiatry 2006; 40: 272-6.

15 Coid J. How many psychiatric patients in prison? Br J Psychiatry 1984; 145 78-86.

16 Bertelsen $M$, Jeppesen P, Petersen L, Thorup A, Ohlenschlaeger J, Le Quach $P$, et al. Five-year follow-up of a randomized multicenter trial of intensive early intervention vs standard treatment for patients with a first episode of psychotic illness: the OPUS trial. Arch Gen Psychiatry 2008; 65: 762-71.

17 McGuffin P, Farmer A, Harvey I. A polydiagnostic application of operational criteria in studies of psychotic illness. Development and reliability of the OPCRIT system. Arch Gen Psychiatry 1991; 48: 764-70.

18 de Koning MB, Bloemen OJ, van Amelsvoort TA, Becker HE, Nieman DH, van der GM, et al. Early intervention in patients at ultra high risk of psychosis: benefits and risks. Acta Psychiatr Scand 2009; 119: 426-42.

19 Marshall M, Rathbone J. Early intervention for psychosis. Cochrane Database Syst Rev 2006; 4: CD004718.

\section{psychiatry in pictures}

\section{Ian Curtis}

\section{Geoff Dickens and Marco Picchioni}

18 May marks the 30th anniversary of the suicide of Ian Curtis, lead singer of Joy Division, who was just 23 when he hanged himself. Curtis's work comprises little more than two dozen songs recorded over 3 years but it remains disproportionately influential. A lineage can be traced from Joy Division through Siouxsie and the Banshees, The Cure, U2, through to contemporary artists such as Interpol and Editors.

Prescribed barbiturates for his poorly controlled epilepsy, Curtis was hospitalised following an overdose 6 weeks before his death. He self-discharged the next day to front the band at a chaotic gig. Curtis's last show at Birmingham University, 2 weeks before his suicide, was featured posthumously on the Joy Division album Still: the song Isolation is notable for the following lyrics: 'I'm ashamed of the things I've been put through, I'm ashamed of the person I am'. Curtis's band mates, however, felt his lyrics did not reflect his state of mind. Curtis had already told his wife that his life's ambition to release one album and one single had been fulfilled, and that he wanted to leave the band and 'join a circus'.

Thirty years on, Curtis's fame outshines that achieved in his brief lifetime. Best known for the single Love will Tear US Apart, released a month after his death - the song features in Rolling Stone's top 500 songs of all time, with Curtis the subject of two feature films, numerous books, documentaries and reissued discs.

The British Journal of Psychiatry (2010) 196, 376. doi: 10.1192/bjp.196.5.376

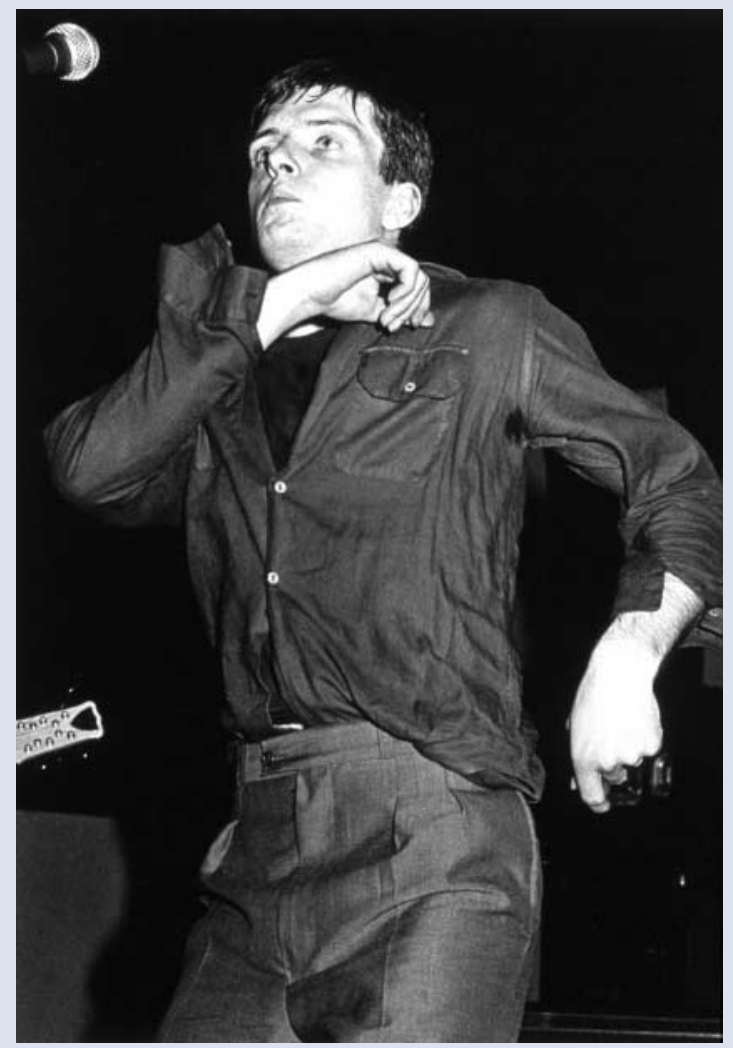

Photo (c) Paul Slattery/Retna 